\title{
Primer caso de dengue autóctono atendido en el Hospital de Enfermedades Infecciosas Dr. Lucio Córdova
}

\author{
PILAR OLEA M. ${ }^{1}$
}

\section{The first case of autochthonous Dengue disease admitted at the Lucio Cordova Infectious Diseases Hospital}

We present the case of a 50 year old male patient with dengue acquired at Easter Island in the summer of 2002. This occurred in the context of the epidemic of this disease, that started on the island in February 2002. The patient had a mild illness and the diagnosis was made by serology (IgM) done by the Reference Laboratory at the Public Health Institute. This patient was the second with a diagnosis of autochthonous dengue and the first to be admitted to a Public Health Service Hospital in Santiago. We briefly review the clinical features and the laboratory tests that contribute to the diagnosis.

Key words: Dengue, Epidemic, Emergent infection.

\section{Introducción}

El dengue es una infección causada por un virus ARN de la familia Flaviviridae. Existen cuatro serotipos entre los cuales no hay inmunidad cruzada pero sí inmunidad homotípica de por vida ${ }^{1}$. Afecta extensas áreas en el mundo incluyendo Centro y Sudamérica, dentro de las cuales se encuentran los países limítrofes con Chile: Perú, Bolivia y Argentina ${ }^{2,3}$. Existen antecedentes de que en 1889 hubo una epidemia de dengue en el norte de Chile, específicamente en la zona de Iquique ${ }^{4}$. Desde entonces no se habían comunicado casos de dengue autóctono en nuestro país.

El principal vector de este virus en la transmisión a humanos es el mosquito Aedes aegypti (Nao Nao entre los aborígenes pascuences) ${ }^{5}$. Este insecto es hematófago y adquiere el virus a través de la picadura a una persona infectada. Después de 8 a 10 días de replicación viral en las glándulas salivales, el mosquito se hace infectante de por vida y lo trasmite al picar a un susceptible ${ }^{1,6}$. En Chile no se había detectado su presencia desde 1915, año en que fue erradicado del norte del país ${ }^{3,4}$. El Ministerio de Salud mantiene una vigilancia epidemiológica a través de la monitorización con larvitrampas en las zonas de mayor riesgo. Este sistema permitió confirmar la reaparición del mosquito en nuestro territorio, específicamente en Isla de Pascua, en el año 2000, situación que había sido ya detectada por la comunidad. Pese a la implementación de medidas de control de la población de mosquitos, su multiplicación continuó y además, adquirió la infección con el virus del dengue, probablemente desde turistas llegados a la zona. Finalmente, en febrero del 2002, aparecieron los primeros casos clínicos de dengue, y en marzo se realizó la primera confirmación diagnóstica de un caso de dengue autóctono.

En esta publicación nos referimos al primer paciente con diagnóstico presuntivo de dengue atendido en un hospital público de Santiago y que constituye el segundo caso confirmado serológicamente en nuestro país. Revisaremos brevemente las formas de presentación, las características del cuadro clínico y el diagnóstico de dengue en base a la literatura médica reciente sobre el tema.

Servicio Clínico Hospital de Enfermedades Infecciosas Dr. Lucio Córdova.

Recibido: 20 diciembre 2002

Aceptado: 8 mayo 2003 


\section{Caso clínico}

Paciente de sexo masculino de 51 años, residente en Santiago, que ingresó al Hospital Lucio Córdova el día viernes 15 de marzo del 2002. Refería múltiples picaduras de mosquito durante su estadía como turista en Isla de Pascua desde el 19 de febrero al 9 de marzo del mismo año. Sus síntomas comenzaron bruscamente el $7 \mathrm{de}$ marzo con sensación febril, calofríos sudoración, cefalea holocranea intensa y fuertes dolores osteomusculares. No consultó médico en la isla y regresó a Santiago el 9 de marzo. A las molestias referidas, se agregaron odinofagia y exantema algo pruriginoso en tronco y extremidades. Alertado por familiares de la detección de casos de dengue en la isla, consultó en un servicio de emergencia los días 14 y 15 de marzo desde donde fue derivado a nuestro hospital. En el momento de su consulta comenzaban a disminuir sus molestias. Al examen físico se constató un paciente en buenas condiciones generales, afebril, con exantema máculo papuloso que comprometía especialmente el tronco. La faringe estaba congestiva y tenía tres pequeñas lesiones úlcero fibrinosas en la mucosa oral. El resto del examen físico se encontraba dentro de límites normales. Sus antecedentes mórbidos incluían hipertensión arterial y apendicectomía. Se planteó la hipótesis diagnóstica de exantema febril en estudio, observación dengue y fue hospitalizado para completar estudio y observar su evolución dada la duda diagnóstica que se planteaba. Se solicitaron exámenes cuyos resultados fueron: Hemograma, hematocrito 40,3\%; hemoglobina: 13,5 mg\%; leucocitos: $4.200 / \mathrm{mm}^{3}$ (56\% granulocitos, $39 \%$ linfocitos); plaquetas: $196.000 / \mathrm{mm}^{3}$ VHS $10 \mathrm{~mm} /$ h; glicemia: $83 \mathrm{mg} \%$; creatininemia: $0,96 \mathrm{mg} \%$; bilirrubinemia total: 0,4 mg\%; GPT: $68 \mathrm{U} / \mathrm{L}(\mathrm{N}$ : 10-50); GOT: $57 \mathrm{U} / \mathrm{L}$ (N: 10-50); FA: $115 \mathrm{U} / \mathrm{L}$ (N: 80-306); Protrombinemia: $100 \%$; orina: eritrocitos 2-3 x campo, leucocitos 4-5 x campo, resto negativo. Detección de IgM anti virus dengue positiva, por técnica de inmunoensayo enzimático (ELISA) realizada en el Instituto de Salud Pública.

El tratamiento sintomático consistió en paracetamol como analgésico y clorfenamina por el prurito que refería.

El paciente evolucionó favorablemente, afebril, con disminución de la cefalea y de los dolores osteomusculares. El exantema cutáneo varió de máculo papuloso a petequial escaso y desapareció rápidamente. Fue dado de alta al quinto día de hospitalización. En el control después de cuatro días de alta refería sentirse muy decaído, con cefalea leve y prurito. El examen físico era normal. Se le indicó clorfenamina y reposo relativo por 7 días adicionales. Asimismo se le explicó cuál sería su probable evolución y se dio de alta, con indicación de control en caso de continuar con alguna molestia. El paciente no regresó a control médico.

\section{Comentario}

La infección por el virus del dengue puede presentarse como:

- Infección asintomática.

- Cuadro febril leve de difícil diferenciación con otros cuadros virales, en especial en los niños.

- Dengue clásico en que se presentan los síntomas y signos más típicos: inicio brusco, fiebre alta, calofríos, cefalea intensa, dolor retro orbitario, fuertes dolores osteomusculares, exantema cutáneo de características variables $^{1,6}$.

- Dengue hemorrágico, cuadro de inicio en todo similar al dengue clásico pero que, en paralelo a la disminución de la fiebre, el paciente se agrava y presenta diversas manifestaciones hemorrágicas y shock ${ }^{6}$.

Los criterios clínicos que define la OMS para el diagnóstico de caso probable de dengue clásico son ${ }^{3}$ :

Cuadro febril de 2 a 7 días de duración asociado a dos o más de las siguientes manifestaciones:

- Cefalea intensa, dolor retro orbitario, mialgias, artralgias y exantema máculo papuloso.

- Manifestaciones hemorrágicas leves como prueba del torniquete positiva, petequias y trombocitopenia. La prueba del torniquete evalúa la fragilidad capilar y consiste en inflar el manguito de presión del esfingomanómetro en el brazo durante 5 minutos y a una presión intermedia entre la sistólica y la diastólica. El test se considera positivo si al cabo de este tiempo han aparecido 3 o más petequias por $\mathrm{cm}^{2}$.

- Existencia de otro caso confirmado y contemporáneo proveniente de la misma localidad.

En el caso del dengue hemorrágico los criterios diagnósticos son:

- Fiebre o historia de cuadro febril reciente.

- Al menos una de las siguientes manifestaciones hemorrágicas: prueba del torniquete positiva, petequias, equimosis o púrpura, sangramiento de mucosas, tracto gastrointestinal, 
sitios de punción u otros.

- Trombocitopenia menor de 100.000 plaquetas/ $\mathrm{mm}^{3}$.

- Aumento de la permeabilidad capilar expresada por:

- incremento del hematocrito en $20 \%$ sobre el promedio para la edad, sexo y población.

- Disminución del hematocrito en $20 \%$ luego de iniciado el tratamiento con reposición de volumen.

- derrame pleural, ascitis.

- hipoalbuminemia.

- Hepatomegalia.

La trombocitopenia y la alteración de la permeabilidad capilar son condiciones indispensables para definir dengue hemorrágico.

El caso relatado corresponde a un cuadro de dengue clásico y presenta la mayoría de los síntomas y signos descritos en esta forma clínica. Sin embargo, en el hemograma no se observaron las alteraciones características: leucopenia, linfocitosis con linfocitos atípicos y trombocitopenia, quizás debido a lo tardío de la consulta y diagnóstico del paciente. Las transaminasas estaban levemente aumentadas como está descrito ${ }^{3,7}$.

Su evolución, como ocurre en la mayoría de los casos de primoinfección, fue autolimitada y favorable, persistiendo con un decaimiento importante en el período de convalecencia. A diferencia de esta forma de presentación benigna de la primoinfección, en una reinfección por otro serotipo, la evolución puede ser más grave y presentarse la forma hemorrágica ${ }^{8}$.

Este caso no nos planteó mayores problemas diagnósticos, pese a no tener ninguna experiencia con esta patología, pues tenía antecedentes epidemiológicos muy claros en un momento de pleno brote epidémico y con síntomas que habían sido bastante típicos. Sin embargo, el cuadro clínico de dengue se puede confundir con una variedad de otras patologías especialmente: influenza por el inicio brusco de un cuadro febril con mialgias, rubéola, meningococcemia si el paciente presenta lesiones cutáneas, malaria por la fiebre brusca con calofríos, septicemia por la fiebre, calofríos, postración y lesiones cutáneas. Además, y de acuerdo al contexto epidemiológico local, puede plantearse el diagnóstico diferencial con otras fiebres hemorrágicas y fiebre amarilla ${ }^{1}$.

Serodiagnóstico. La detección de $\operatorname{IgM}$ anti virus dengue en una muestra aislada, tomada entre 6 y 21 días desde el inicio de la enfermedad, también es criterio de caso probable ${ }^{7}$, aunque un título positivo de IgM hace altamente probable el diagnóstico de dengue en una persona que no habita en zonas endémicas ${ }^{3}$.

Para confirmar un caso se debe contar con alguno de los siguientes exámenes ${ }^{3}$ :

- Aislamiento del virus del dengue de la sangre del paciente.

- Histoquímica positiva en muestras de tejidos,

- Detección del ácido nucleico viral mediante RPC

- Aumento en cuatro veces de los títulos de IgG o IgM.

En este paciente no se intentó aislamiento viral, por el tiempo de evolución que llevaba en el momento de consultar. Para aislar el virus debe obtenerse la muestra durante el periodo de viremia que dura como máximo hasta el quinto día de evolución de los síntomas ${ }^{7}$. En Chile están actualmente disponibles tanto la serología como el aislamiento viral y la técnica de RPC, aunque estos dos últimos sólo con fines de investigación ${ }^{3}$.

En la actualidad no se dispone de tratamiento específico para el dengue, siendo sólo sintomático. El paciente debe permanecer en reposo, con analgésicos y antipiréticos evitando el ácido acetilsalicílico y otros antiinflamatorios no esteroidales que alteran la función plaquetaria ${ }^{7}$. Se debe vigilar la hidratación, volumen urinario, presión arterial, hematocrito y recuento de plaquetas, siendo necesario mantener un buen aporte de volumen, ya sea oral o endovenoso. En el caso del dengue hemorrágico es fundamental el manejo precoz y adecuado del shock ${ }^{1}$.

En Isla de Pascua, se identificó el serotipo 1 como el causante del brote epidémico. El MINSAL ha tomado las medidas necesarias para la eliminación del mosquito, siendo ésta la principal acción epidemiológica para el control de esta infección ${ }^{3}$. Esta medida, la disminución de los susceptibles, y probablemente el término del verano, lograron detener el brote epidémico. Sin embargo, la erradicación del Aedes aegypti no es una tarea sencilla ni rápida y probablemente pasarán algunos años antes de que esto se logre.

Es importante tener presente que este mismo insecto transmite la fiebre amarilla, siendo necesario estar alerta a la posible aparición de esta enfermedad en Isla de Pascua. A diferencia del dengue para el cual no existe vacuna disponible en la actualidad ${ }^{2}$, para la fiebre amarilla sí existe una vacuna eficaz. En todo caso la erradicación del mosquito de la isla y las medidas epidemiológicas para evitar que éste llegue al territorio continental son las tareas más importantes en este momento. 


\section{Resumen}

Se presenta el caso de un paciente de sexo masculino de 51 años con cuadro clínico de dengue contraído en Isla de Pascua durante el verano del 2002. Este caso se produjo durante la epidemia de esta enfermedad, que ocurrió en ese territorio, a partir de febrero- marzo de ese año. El paciente tuvo una evolución favorable y su diagnóstico fue confirmado mediante serología (IgM) en el Instituto de Salud Pública (ISP). Fue el segundo caso de dengue autóctono diagnosticado durante la epidemia, y el primero en ser atendido en un hospital del servicio público de salud de Santiago. Se revisa brevemente el cuadro clínico y criterios diagnósticos para esta enfermedad.

\section{Bibliografía}

1.- Isturiz R, Gubler D, Brea Del Castillo S. Dengue and Dengue hemorrhagic fever in Latin America and the
Caribbean. Infect Dis Clin North Am 2000; 14: 12140.

2.- Jelinek T. Dengue fever in international travelers. Clin Infect Dis 2000; 31: 144-7.

3.- Comité de Infecciones Emergentes. Sociedad Chilena de Infectología. Dengue. Rev Chil Infect 1999; 16: 220-34.

4.- Laval E. ¿Hubo Dengue autóctono en Chile? Rev Chil Infect 2001;1: 69-71.

5.- Documento ISP. Dengue en http://epi.minsal.cl/epi/ htm/enter/Dengue.htm. Accedido con fecha 13 de diciembre 2002.

6.- Tsai TF, Flavivirus, Mandell, Douglas and Bennett's Enfermedades Infecciosas Principios y Práctica. Mandell GL, Bennettt JE and Dolin R, eds. $5^{\circ}$ edición, Buenos Aires, Editorial Médica Panamericana, pp: 2002, 2091-116.

7.- Revisión del CDC Sección de Enfermedades Infecciosas transmitidas por vectores. Dengue aspectos clínicos y de Salud Pública. Mayo 2002 en www.cdc.gov/ ncidod/diseases/submenus/sub_dengue.htm. Accedido con fecha 13 de diciembre 2002.

8.- Kalayanarooj S, Vaughndn W, Nimmannitya $\mathrm{S}$ et al. Early clinical and laboratory indicators of acute Dengue Illness. J Infect Dis 1997; 176: 313-21.

Correspondencia a:

Pilar Olea Meneses

E-mail: sepuolea@entelchile.net 